\title{
Toward Understanding the Biodiversity of Gromiids: the Fine Structure of Gromia sp. from Zane Grey Creek, Florida Keys
}

\author{
Susan T. Goldstein, ${ }^{*}$ Samuel S. Bowser, ${ }^{* *}$, and Elizabeth A. Richardson*** \\ * Dept. of Geology, University of Georgia, Athens, GA 30602 \\ ** Wadsworth Center, N. Y. State Dept. of Health, P. O. Box 509, Albany, NY 12201-0509 \\ *** Dept. of Plant Biology, University of Georgia, Athens, GA 30602
}

Gromiids are testate rhizarian protists with widespread occurrences in shallow to deep marine settings and occasional reports from freshwater systems as well [1-2]. These abundant but poorly understood organisms are characterized by filose pseudopodia and a transparent singlechambered test with one, or rarely, several distinctive apertures. The cell body is generally amber to reddish brown and packed with stercomata which are small spherical packets of clayrich sediment and detritus. Gromiids vary in size from several hundred microns to several centimeters. Because the shallow marine representatives share broad gross morphological similarities, historically they have been assigned to just a single species, Gromia oviformis Dujardin. However, this species was described in the early $19^{\text {th }}$ Century from multiple European locales, and no type specimen was designated resulting in taxonomic ambiguity.

Shallow-water gromiids are common and very widely distributed [3]. We know very little about the biodiversity of gromiids, but collectively, recent studies show that they are not a taxonomic monolith. Rather, multiple species occur in both shallow and deep marine settings with subtle differences in morphology and distinct SSU rDNA sequences [1, 4-6]. Here we report on the fine structure, prepared using high-pressure freezing and freeze substitution [7], of a gromiid that is very common in mangrove creeks, particularly Zane Grey Creek, of the central Florida Keys. This gromiid (Fig. $1 \& 2$ ) is especially abundant in stands of the alga Batophora that lives on prop-roots of the red mangrove. Like other gromiids, the cell body is packed with numerous stercomata (Fig. 3), and the test (shell) is composed of multiple layers (Fig. $4 \& 5$ ): an outer finely fibrous, mesh-like layer with numerous canals, and an inner layer of "honeycomb membranes." The character of the outer surface of the test differs from the few described species. It is covered by a fine mesh and has a series of raised regions, each of which surrounds a pore that opens into a canal. The outer surface may be clean, or with attached clay platelets and inhabited by numerous bacteria and/or various microbial eukaryotes. Filose pseudopodia exit via a single aperture (Fig. 6) which has a distinctive "collar" that can be opened and closed. Additional study on the many disparate populations of gromiids should provide a foundation for understanding gromiid biodiversity and for understanding their ecology.

[1] N. Rothe et al., Zool. J. Linnean Soc. 157 (2009) 451.

[2] J. Leidy, USGS Survey of the Territories. 12 (1879) 277.

[3] Z. M. Arnold, Univ. Calif. Publ. Zool. 100 (1972) 1.

[4] A. J. Gooday and S. S. Bowser, Protist 156 (2005) 113.

[5] A. da Silva et al., Marine Biol. 148 (2006) 769.

[6] A. da Silva and A. J. Gooday, Deep-Sea Res. II, 56 (2009) 422.

[7] S. T. Goldstein and E.A. Richardson, J. Foram. Res. (2002) 375. 


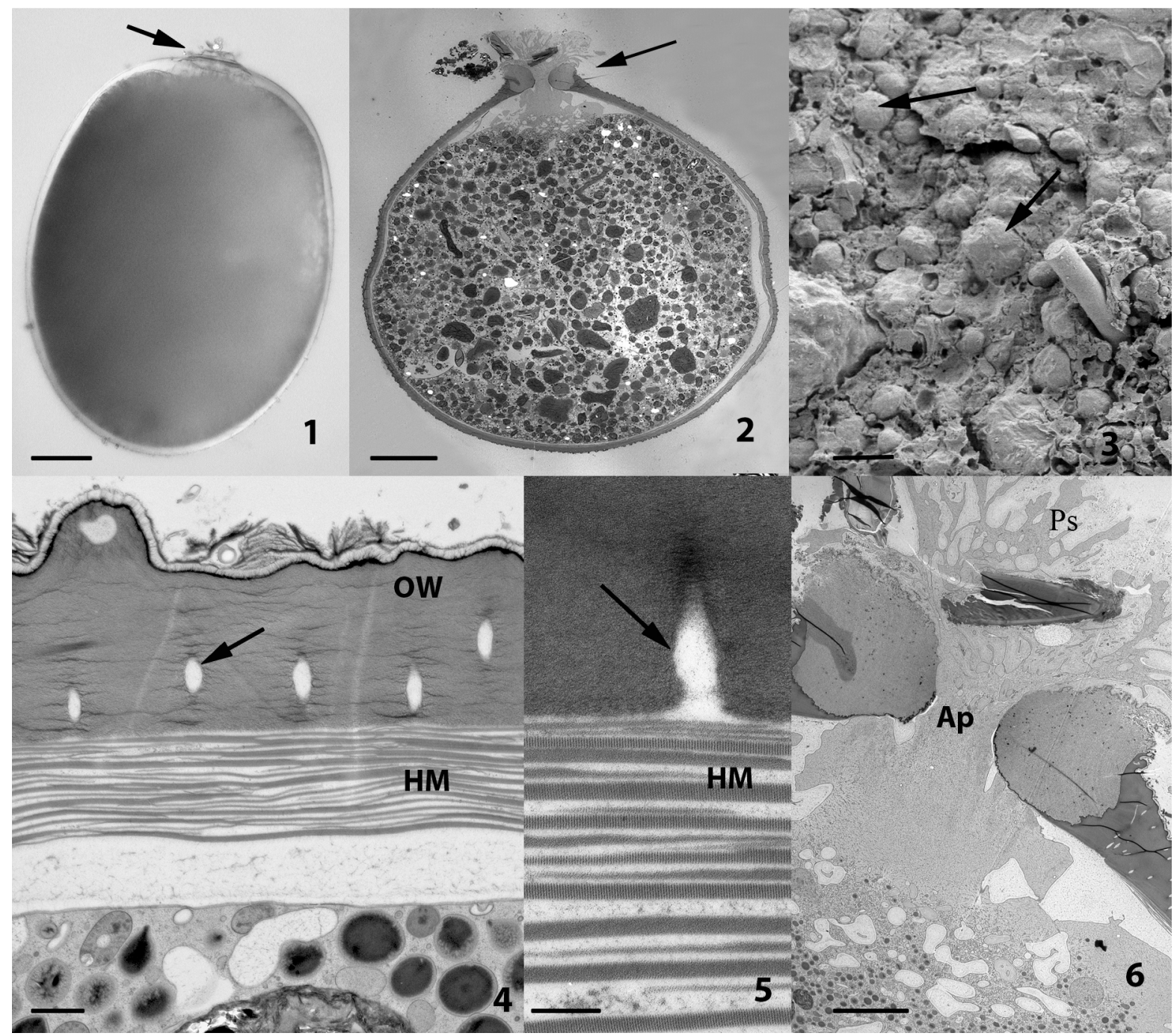

Fig. 1. Reflected light micrograph of Gromia sp. from Zane Grey Creek, Florida Keys. The single aperture located at the top (arrow). Scale bar $=50$ microns.

Fig. 2. Low-magnification TEM of entire organism. Section passes through the aperture (arrow). Scale bar $=50$ microns.

Fig. 3. SEM of a fractured surface through the cell body. Note numerous stercomata (arrows). Scale bar $=10$ microns.

Fig. 4. TEM of equatorial section through the organism showing features of the wall: outer mesh-like wall (OW) with canals (arrow), and inner layer of honeycomb membranes $(\mathrm{HM})$. Scale bar $=1$ micron.

Fig. 5. TEM showing boundary between inner (HM) and outer wall layers. Canal (arrow) opens at the base of the outer layer. Scale bar $=0.25$ microns.

Fig. 6. Low-magnification TEM of the single aperture (Ap) with filose pseudopodia emerging (Ps). Scale bar $=10$ microns. 